\title{
PENYELEKSIAN JURUSAN TERFAVORIT PADA SMK SIRAJUL FALAH DENGAN METODE SAW
}

\author{
Siti Nurlela'; ${ }^{1}$ Akmaludin²; Sri Hadianti³; Lestari Yusuf ${ }^{4}$ \\ ${ }^{1}$ Program Studi Ilmu Komputer \\ STMIK Nusa Mandiri Jakarta \\ www.nusamandiri.ac.id \\ siti.sie@nusamandiri.ac.id \\ ${ }^{2}$ Program Studi Sistem Informasi \\ STMIK Nusa Mandiri Jakarta \\ www.nusamandiri.ac.id \\ akmaludin@nusamandiri.ac.id \\ 3Program Studi Ilmu Komputer \\ STMIK Nusa Mandiri Jakarta \\ www.nusamandiri.ac.id \\ srihadianti07@gmail.com \\ ${ }^{4}$ Program Studi Sistem Informasi \\ STMIK Nusa Mandiri Jakarta \\ www.nusamandiri.ac.id \\ lestari.lyf@nusamandiri.ac.id
}

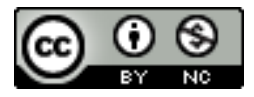

Ciptaan disebarluaskan di bawah Lisensi Creative Commons Atribusi-NonKomersial 4.0 Internasional.

\begin{abstract}
SMK Sirajul Falah is a Vocational High School located in the Bogor area. However, the selection of the favorite majors in SMK Sirajul Falah is still qualitative so that the process of choosing the favorite majors become not accurate. This is what makes the need for a method that is able to manage the data of the selection of the favorite majors and generate ranking of the calculation of the weight of the selection of the favorite majors. In the selection of this favorite majors, there is a method of Simple Additive Weighting (SAW) which can be used in quantitative problem solving. The SAW method is used to compare each criterion with one another, so as to give the results of the favorite majors and provide an assessment of each department at the Sirajul Falah Vocational School.
\end{abstract}

Keywords: Selection of the Favorite Department, SAW Method.

Intisari - SMK Sirajul Falah merupakan Sekolah Menengah Kejuruan swasta yang berada di wilayah Bogor. Akan tetapi penyeleksian jurusan terfavorit di SMK Sirajul Falah masih bersifat kualitatif sehingga pada proses pemilihan jurusan terfavorit menjadi belum akurat. Hal ini yang menjadikan perlunya sebuah metode yang mampu mengelola data penyeleksian jurusan terfavorit dan menghasilkan ranking dari perhitungan bobot penyeleksian jurusan terfavorit tersebut. Dalam penyeleksian jurusan terfavorit ini, terdapat metode Simple Additive Weighting (SAW) yang dapat digunakan dalam pemecahan masalah yang bersifat kuantitatif. Metode SAW ini digunakan untuk membandingkan masing-masing kriteria satu dengan yang lain, sehingga memberikan hasil jurusan terfavorit dan memberikan penilaian terhadap setiap jurusan pada SMK Sirajul Falah.

Kata kunci : Penyeleksian Jurusan Terfavorit, Metode SAW.

\section{PENDAHULUAN}

Menurut Peraturan Pemerintah Republik Indonesia Nomor 17 tahun 2010 tentang Pengelolaan Pendidikan danPenyelenggaraan Pendidikan, Sekolah Menengah Kejuruan yang kemudian disingkat SMK, adalah salah satu bentuk satuan pendidikan formal yang 
menyelenggarakan pendidikan kejuruan pada jenjang pendidikan menengah sebagai lanjutan dari SMP, MTS, atau bentuk lain yang sederajat atau lanjutan dari hasil belajar yang diakui sama atau setara SMP atau MTS. Dalam hal ini penulis terfokus dalam hal penyeleksian jurusan terfavorit pada SMK Sirajul Falah Parung. SMK Sirajul Falah merupakan Sekolah Menengah Kejuruan swasta yang berada di wilayah Bogor yang selalu berupaya dalam peningkatan mutu baik internal maupun eksternal secara berkelanjutan agar dapat bersaing dengan sekolah menengah kejuruan lain. Salah satu upaya yang dilakukan adalah dengan menyediakan jurusan yang beragam untuk siswasiswanya. Akan tetapi penyeleksian jurusan terfavorit di SMK Sirajul Falah masih bersifat kualitatif sehingga pada proses pemilihan jurusan terfavorit menjadi belum akurat. (Pare, 2013) menyebutkan bahwa Kesalahan memilih program studi berdampak yang signifikan terhadap kehidupan anak di masa mendatang. Salah satu dampak yang ditimbulkan adalah si anak akan menjalani aktivitasnya yaitu belajar dengan terpaksa, atau anak akan gagal dalam studi. Hal ini yang menjadikan perlunya sebuah metode yang mampu mengelola data penyeleksian jurusan terfavorit dan menghasilkan ranking dari perhitungan bobot penyeleksian jurusan terfavorit tersebut.

Menurut (Rosadi \& Khotijah, 2017) menyebutkan "banyaknya tenaga kerja yang memiliki kemampuan yang berbeda-beda, maka dalam merekrut karyawan baru diperlukan penyeleksian dari calon karyawan yang memenuhi kriteria dan kebutuhan, sistem pendukung keputusan menggunakan metode SAW (Simple Additive Weighting) membantu mempermudah pengambilan keputusan bagian penyeleksian karyawan" Persaingan para karyawan yang semakin ketat membuat sebuah keputusan kenaikan pangkat semakin sulit untuk diputuskan, terutama jika ada beberapa karyawan yang memiiki kemampuan yang tidak jauh berbeda. Pengambilan keputusan yang tidak adil dapat menimbulkan dampak buruk bagi suatu perusahaan (Frieyadie, 2016). Dalam penyeleksian jurusan terfavorit ini, terdapat metode Simple Additive Weighting (SAW) yang dapat digunakan dalam pemecahan masalah yang bersifat kuantitatif.

\section{BAHAN DAN METODE}

\section{Penyeleksian}

Menurut (Tim Pustaka Phoenik, 2012) seleksi diartikan sebagai pilihan, pemilihan; saringan.
Sedangkan (Yuniarsih \& Suwatno, 2011) mengemukakan bahwa Proses seleksi merupakan rangkaian tahap-tahap khusus yang digunakan untuk memutuskan pelamar mana yang akan diterima.

\section{Sistem Pendukung Keputusan}

Sistem merupakan kumpulan elemen yang saling berkaitan yang bertanggung jawab memproses masukan (input) sehingga menghasilkan keluaran (output).

Keputusan merupakan kegiatan memilih suatua strategi atau tindakan dalam pemecahan masalah teresbut". Tujuan dari keputusan adalah untuk mencapai target atau aksi tertentu yang harus dilakukan.

Kriteria atau ciri-ciri dari keputusan adalah :

1. Banyak pilihan/alternatif

2. Ada kendala atau syarat

3. Mengikuti suatu pola/model tingkah laku, baik yang terstruktur maupun tidak terstruktur

4. Banyak input/variable

5. Ada factor risiko

6. Dibutuhkan kecepatan, ketepatan dan keakuratan

Sistem Pendukung Keputusan atau Decision Support Sistem (DSS) merupakan sistem informasi interaktif yang menyediakan informasi, pemodelan dan pemanipulasi data". Sistem ini digunakan untuk membantu pengambilan keputusan dalam situasi yang semiterstruktur dan situasi yang tidak terstruktur, dimana tak seorang pun tahu secara pasti bagaimana keputusan seharusnya dibuat. (Kusrini, 2007)

\section{Metode Simple Additive Weighting (SAW)}

(Hartoyo, 2013) Mengemukakan bahwa Metode SAW dikenal istilah metode penjumlahan terbobot. Konsep dasar metode SAW adalah mencari penjumlahan terbobot dari rating kinerja pada setiap alternatif pada semua atribut.

Metode SAW adalah metode Simple Additive Weighting sering disebut dikenal dengan metode penjumlahan terbobot." (Ikhwan, Nofriansyah, \& Sriani, 2015)

Serta (Elistri, Wahyudi, \& Supardi, 2014) menyebutkan bahwa Sistem pendukung keputusan ini dibuat untuk membantu dalam pembuatan keputusan pemilihan jurusan pada siswa SMA Negeri 8 Seluma.

Konsep dasar metode Simple Additive Weighting ini adalah mencari penjumlahan terbobot dari rating kinerja pada setiap alternatif semua atribut. Langkah-langkah penyeleksian metode Simple Additive Weighting adalah sebagai berikut: 
1. Menentukan kriteria-kriteria yang akan dijadikan acuan dalam pengambilan keputusan, yaitu $\mathrm{Ci}$

2. Menentukan rating kecocokan setiap alternatif pada setiap kriteria

3. Membuat matriks keputusan berdasarkan kriteria (Ci), kemudian melakukan normalisasi matriks berdasarkan persamaan yang disesuaikan dengan jenis atribut (atribut keuntungan ataupun atribut biaya) sehingga diperoleh matriks ternormalisasi $R$

4. Hasil akhir diperoleh dari proses perankingan yaitu: penjumlahan dari pekalian matriks ternormalisasi $\mathrm{R}$ dengan vector bobot sehingga diperoleh nilai terbesar yang dipilih sebagai alternatif terbaik (Ai) sebagai solusi.

Formula untuk melakukan normalisasi adalah sebagai berikut:

$r_{i j}=\left\{\begin{array}{l}\frac{\mathrm{X}_{\mathrm{ij}}}{\operatorname{Max}_{\mathrm{i}} \mathrm{X}_{\mathrm{ij}}} \text { Jika } \mathrm{j} \text { adalah atribut keuntungan (benefit) } \\ \frac{\operatorname{Min}_{\mathrm{i}} \mathrm{X}_{\mathrm{ij}}}{\mathrm{X}_{\mathrm{ij}}} \quad \text { Jika } \mathrm{j} \text { adalah atribut biaya (cost) }\end{array}\right.$

(Astuti \& Isna Zahrotul Fu'ad, 2017) Menyatakan bahwa Metode SAW membutuhkan proses normalisasi matriks keputusan (X) ke suatu skala yang dapat diperbandingkan dengan semua rating alternatif yang ada.

Formula untuk melakukan normalisasi metode SAW

adalah sebagai berikut :

rij : Nilai rating kinerja ternormalisasi

xij $\quad$ : Nilai atribut yang dimiliki dari setiap kinerja

Maxi xij : Nilai terbesar dari setiap kriteria

Mini xij : Nilai terkecil dari setiap kriteria

Benefit : Jika nilai terbesar adalah terbaik

Cost : Jika nilai terkecil adalah terbaik

Dimana rij adalah rating kinerja ternormalisasi

dari

alternatif $\mathrm{Ai}$ pada atribut $\mathrm{Cj} ; \mathrm{i}=1,2, \ldots, \mathrm{m}$ dan $\mathrm{j}=1,2, \ldots ., \mathrm{n}$.

Nilai preferensi untuk setiap alternatif (Vi) diberikan sebagai :

$V i=\sum_{j=i}^{n} w j r i j$

Keterangan :

Vi : Rangkaian untuk setiap alternatif

Wj : Nilai bobot dari setiap kriteria

Rij : Nilai rating kinerja ternormalisasi

Nilai Vi yang lebih besar mengindikasikan bahwa aternatif Ai lebih terpilih.

\section{HASIL DAN PEMBAHASAN}

Dalam pengolahan hasil penelitian, penulis menetapkan langkah-langkah penyelesaian yang sesuai dengan langkah-langkah Simple Additive Weight (SAW) dimana ada empat tahap, yaitu menentukan kriteria yang akan dijadikan acuan, menentukan rating kecocokan setiap alternatif pada setiap kriteria, membuat matriks keputusan dan perankingan.

\section{Menentukan Kriteria}

Tahapan menentukan kriteria dipakai dalam memilih suatu alternatif dan memecah masalah yang kompleks atau tidak terstruktur dalam sub-sub masalah lalu menyusunnya menjadi suatu hirarki. Dalam hirarki ini dibuat menjadi 3 bagian yaitu tujuan, kriteria dan alternatif.

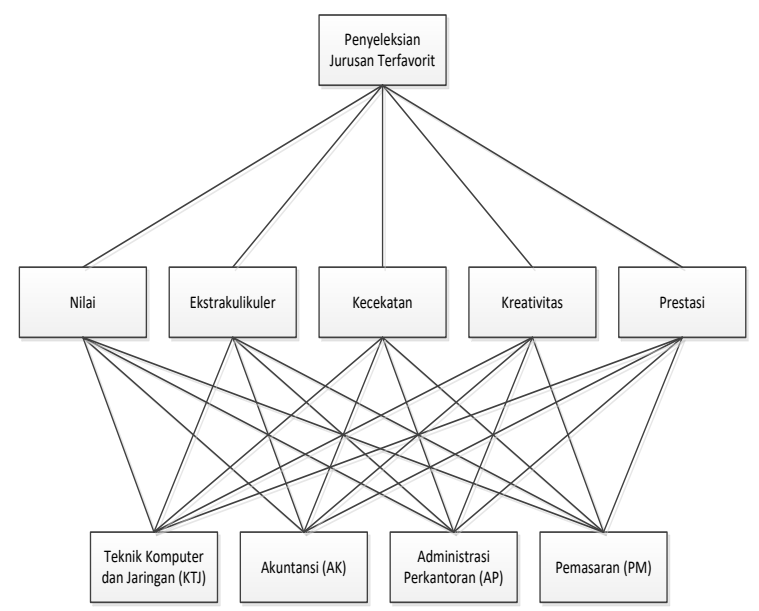

Sumber: (Nurlela, Akmaludin, Hadianti, Yusuf, \& Hermanto, 2018)

Gambar 1. Hirarki Penyeleksian Jurusan Terfavorit

Tabel 1. Nilai dan Bobot untuk Kriteria

\begin{tabular}{ccc}
\hline \multicolumn{3}{c}{ C1, C2, C3, C4 dan C5 } \\
\hline Nilai & Nilai & \\
Tertulis & Bobot & Keterangan Bobot \\
\hline $81-100$ & 5 & Sangat Baik \\
\hline $61-80$ & 4 & Baik \\
\hline $41-60$ & 3 & Cukup \\
\hline $21-40$ & 2 & Buruk \\
\hline Jan-20 & 1 & Sangat Buruk \\
\hline
\end{tabular}

Sumber: (Nurlela, Akmaludin, Hadianti, Yusuf, \& Hermanto, 2018)

Untuk pemberian bobot setiap kriteria adalah $\mathrm{C} 1=5, \mathrm{C} 2=5, \mathrm{C} 3=4, \mathrm{C} 4=4, \mathrm{C} 5=3$. Adapun bobot dari setiap kriteria dalah sebagai berikut: 
Tabel 2. Bobot Kriteria

\begin{tabular}{ccc}
\hline No & Kriteria & Bobot \\
\hline 1 & Nilai & 0,25 \\
\hline 2 & Ekstra Kulikuler & 0,25 \\
\hline 3 & Kecekatan & 0,2 \\
\hline 4 & Kreatifitas & 0,2 \\
\hline 5 & Prestasi & 0,1 \\
\hline
\end{tabular}

Sumber: (Nurlela, Akmaludin, Hadianti, Yusuf, \& Hermanto, 2018)

\section{Menentukan Rating Kecocokan}

Langkah kedua, menentukan rating kecocokan dari setiap alternatif pada setiap kriteria yang ditunjukan pada tabel dibawah ini :

Tabel 3. Rating Kecocokan

\begin{tabular}{cccccc}
\hline \multirow{2}{*}{ Alternatif } & \multicolumn{5}{c}{ Hasil Penelitian } \\
\cline { 2 - 6 } & C1 & C2 & C3 & C4 & C5 \\
\hline A1 & 68 & 43 & 4 & 4 & 2 \\
\hline A2 & 72 & 86 & 4 & 4 & 3 \\
\hline A3 & 65 & 73 & 4 & 4 & 3 \\
\hline A4 & 57 & 73 & 4 & 4 & 3 \\
\hline
\end{tabular}

Sumber: (Nurlela, Akmaludin, Hadianti, Yusuf, \& Hermanto, 2018)

\section{Membuat Matriks Keputusan}

Setelah nilai rating alternatif ditemukan, langkah ketiga pembentukan matriks keputusan (x) yang dibentuk dari tabel rating kecocokan dari setiap alternatif pada setiap kriteria.

$$
\left[\begin{array}{lllll}
4 & 3 & 4 & 4 & 2 \\
4 & 5 & 4 & 4 & 3 \\
4 & 4 & 4 & 4 & 3 \\
3 & 4 & 4 & 4 & 3
\end{array}\right]
$$

Sumber: (Nurlela, Akmaludin, Hadianti, Yusuf, \& Hermanto, 2018)

Gambar 2. Matriks Keputusan

Selanjutnya menghitung nilai normalisasi dari setiap alternative adalah sebagai berikut :

Alternatif 1

$$
\begin{aligned}
& r_{11}=\frac{4}{\operatorname{Max}\{4 ; 4 ; 4 ; 3 ;\}}=\frac{4}{4}=1,00 \\
& r_{12}=\frac{3}{\operatorname{Max}\{3 ; 5 ; 4 ; 4 ;\}}=\frac{3}{5}=0,60 \\
& r_{13}=\frac{4}{\operatorname{Max}\{4 ; 4 ; 4 ; 4 ;\}}=\frac{4}{4}=1,00 \\
& r_{14}=\frac{4}{\operatorname{Max}\{4 ; 4 ; 4 ; 4 ;\}}=\frac{4}{4}=1,00 \\
& r_{15}=\frac{2}{\operatorname{Max}\{2 ; 3 ; 3 ; 3 ;\}}=\frac{2}{3}=0,67
\end{aligned}
$$

$\underline{\text { Alternatif } 2}$

$$
\begin{aligned}
& r_{21}=\frac{4}{\operatorname{Max}\{4 ; 4 ; 4 ; 3 ;\}}=\frac{4}{4}=1,00 \\
& r_{22}=\frac{5}{\operatorname{Max}\{3 ; 5 ; 4 ; 4 ;\}}=\frac{5}{5}=1,00 \\
& r_{23}=\frac{4}{\operatorname{Max}\{4 ; 4 ; 4 ; 4 ;\}}=\frac{4}{4}=1,00 \\
& r_{24}=\frac{4}{\operatorname{Max}\{4 ; 4 ; 4 ; 4 ;\}}=\frac{4}{4}=1,00 \\
& r_{25}=\frac{3}{\operatorname{Max}\{2 ; 3 ; 3 ; 3 ;\}}=\frac{3}{3}=1,00
\end{aligned}
$$

$\underline{\text { Alternatif } 3}$

$$
\begin{aligned}
& r_{31}=\frac{4}{\operatorname{Max}\{4 ; 4 ; 4 ; 3 ;\}}=\frac{4}{4}=1,00 \\
& r_{32}=\frac{4}{\operatorname{Max}\{3 ; 5 ; 4 ; 4 ;\}}=\frac{4}{5}=0,80 \\
& r_{33}=\frac{4}{\operatorname{Max}\{4 ; 4 ; 4 ; 4 ;\}}=\frac{4}{4}=1,00 \\
& r_{34}=\frac{4}{\operatorname{Max}\{4 ; 4 ; 4 ; 4 ;\}}=\frac{4}{4}=1,00 \\
& r_{35}=\frac{3}{\operatorname{Max}\{2 ; 3 ; 3 ; 3 ;\}}=\frac{3}{3}=1,00
\end{aligned}
$$

Alternatif 4

$$
\begin{aligned}
& r_{41}=\frac{3}{\operatorname{Max}\{4 ; 4 ; 4 ; 3 ;\}}=\frac{3}{4}=0,75 \\
& r_{42}=\frac{4}{\operatorname{Max}\{3 ; 5 ; 4 ; 4 ;\}}=\frac{4}{5}=0,80 \\
& r_{43}=\frac{4}{\operatorname{Max}\{4 ; 4 ; 4 ; 4 ;\}}=\frac{4}{4}=1,00 \\
& r_{44}=\frac{4}{\operatorname{Max}\{4 ; 4 ; 4 ; 4 ;\}}=\frac{4}{4}=1,00 \\
& r_{45}=\frac{3}{\operatorname{Max}\{2 ; 3 ; 3 ; 3 ;\}}=\frac{3}{3}=1,00
\end{aligned}
$$

Hasil dari perhitungan nilai normalisasi dari setiap alternatif adalah sebagai berikut :

$$
\left[\begin{array}{lllll}
1,00 & 0,60 & 1,00 & 1,00 & 0,67 \\
1,00 & 1,00 & 1,00 & 1,00 & 1,00 \\
1,00 & 0,80 & 1,00 & 1,00 & 1,00 \\
0,75 & 0,80 & 1,00 & 1,00 & 1,00
\end{array}\right]
$$

Sumber: (Nurlela, Akmaludin, Hadianti, Yusuf, \& Hermanto, 2018)

Gambar 3. Matriks Keputusan

\section{Perankingan}

Langkah keempat yaitu, menghitung hasil akhir nilai preferensi $\left(\mathrm{V}_{\mathrm{i}}\right)$ diperoleh dari penjumlahan dari perkalian elemen baris matriks ternormalisasi (R) dengan bobot preferensi (W). adapun bobot yang digunakan adalah sebagai berikut :

$$
W=\left[\begin{array}{lllll}
0,25 & 0,25 & 0,20 & 0,20 & 0,10
\end{array}\right]
$$

$V 1=(0,25 \times 1,00)+(0,25 \times 0,60)+$ $(0,20 \times 1,00)+(0,20 \times 1,00)+(0,10 \times 0,67)$ 


$$
\begin{aligned}
& =0,25+0,15+0,20+0,20+0,67 \\
& =0,867 \\
& V 2=(0,25 \times 1,00)+(0,25 \times 1,00)+ \\
& (0,20 \times 1,00)+(0,20 \times 1,00)+(0,10 \times 1,00) \\
& =0,25+0,25+0,20+0,20+0,10 \\
& =1,00 \\
& V 3=(0,25 \times 1,00)+(0,25 \times 0,80)+ \\
& (0,20 \times 1,00)+(0,20 \times 1,00)+(0,10 \times 1,00) \\
& =0,25+0,20+0,20+0,20+0,10 \\
& =0,95 \\
& V 4=(0,25 \times 0,75)+(0,25 \times 0,80)+ \\
& (0,20 \times 1,00)+(0,20 \times 1,00)+(0,10 \times 1,00) \\
& =0,1875+0,20+0,20+0,20+0,10 \\
& =0,8875
\end{aligned}
$$

Tabel 4. Hasil Perankingan

\begin{tabular}{ccccc}
\hline $\begin{array}{c}\text { Alternati } \\
\mathrm{f}\end{array}$ & Hasil & $\begin{array}{c}\text { Hasil } \\
\text { Akhir }\end{array}$ & $\begin{array}{c}\text { Presen } \\
\text { tase }\end{array}$ & $\begin{array}{c}\text { Ran } \\
\text { king }\end{array}$ \\
\hline TKJ & 0,867 & 0,23404 & $23 \%$ & 4 \\
\hline AK & 1 & 0,26994 & $27 \%$ & 1 \\
\hline AP & 0,95 & 0,25644 & $26 \%$ & 2 \\
\hline PM & 0,8875 & 0,23957 & $24 \%$ & 3 \\
\hline Jumlah & 3,7045 & 1 & $100 \%$ &
\end{tabular}

Sumber: (Nurlela, Akmaludin, Hadianti, Yusuf, \& Hermanto, 2018)

Diantara $V_{1}, V_{2}, V_{3}$, dan $V_{4}$ nilai terbesar adalah $V_{2}$, sehingga alternatif yang terpilih dan berhak menjadi jurusan terfavorit SMK Sirajul Falah adalah $\mathbf{V}_{\mathbf{2}}=$ Akuntansi dengan hasil $\mathbf{2 7 \%}$.

\section{KESIMPULAN}

Berdasarkan penelitian yang dilakukan penulis, Untuk menentukan jurusan terfavorit pada SMK Sirajul Falah dapat menggunakan data-data kuantitatif seperti data nilai, ekstra kulikuler, kecekatan, kreatifitas dan prestasi dari masing-masing jurusan, yaitu : Teknik Komputer \& Jaringan (TKJ), Akuntansi (AK), Administrasi Perkantoran (AP) dan Pemasaran (PM). Perhitungan jurusan terfavorit pada SMK Sirajul Falah dapat menggunakan metode Simple Additive Weight, maka terpilih satu jurusan yang akan menjadi jurusan terfavorit pada SMK Sirajul Falah yaitu jurusan Akuntasi. Dengan hasil akhir $27 \%$.

\section{REFERENSI}

Astuti, Y., \& Isna Zahrotul Fu'ad. (2017). Penentuan Karyawan Terbaik Menggunakan Metode Simple Additive
Weighting Pada PT. Patra Nur Alaska. Seminar Nasional Tekhnologi Informasi Dan Multimedia, 37-42.

Elistri, M., Wahyudi, J., \& Supardi, R. (2014). Penerapan Metode Saw Dalam Sistem Pendukung Keputusan Pemilihan Jurusan Pada Sekolah Menengah Atas Negeri 8 Seluma. Jurnal Media Infotama Penerapan Metode SAW... ISSN, 10(2), 1858-2680.

Frieyadie, F. (2016). Penerapan Metode Simple Additive Weight (SAW) Dalam Sistem Pendukung Keputusan Promosi Kenaikan Jabatan. Jurnal Pilar Nusa Mandiri, 12(1), 37-45.

Hartoyo, R. (2013). PERANCANGAN SISTEM PENDUKUNG KEPUTUSAN MENETUKAN STATUS KARYAWAN KONTRAK SALES PROMOTION GIRL MENJADI KARYAWAN TETAP DENGAN METODE SIMPLE ADDITIVE WEIGHTING. Pelita Informatika: Informasi Dan Informatika, 4(3), 59-64. Retrieved from http://www.stmikbudidarma.ac.id/ejurnal/index.php/pelita/ article/view/295

Ikhwan, A., Nofriansyah, D., \& Sriani. (2015). Penerapan Data Mining dengan Algoritma Fp-Growth untuk Mendukung Strategi Promosi Pendidikan ( Studi Kasus Kampus STMIK Triguna Dharma ). Saintikom, 14(3), 211-226.

Kusrini. (2007). Konsep dan Aplikasi Sistem Pendukung Keputusan. Andi Offset (1st ed.). Yogyakarta: Andi Publisher.

Nurlela, S., Akmaludin, A., Hadianti, S., Yusuf, L., \& Hermanto, H. (2018). Laporan Akhir Penelitian - Penyeleksian Jurusan Terfavorit Pada Smk Sirajul Falah Dengan Metode SAW. Jakarta.

Pare, S. (2013). Sistem Pendukung Keputusan Pemilihan Program Studi Pada Perguruan Tinggi. Jurnal Ilmiah Mustek Anim Ha, 2(1), 58-70.

Rosadi, D., \& Khotijah, S. (2017). Seleksi Penerimaan Karyawan dengan Metode Simple Additive Weighting ( SAW ) ( Studi Kasus Toko Markas Hobby ), 11(1), 39-46.

Tim Pustaka Phoenik. (2012). Kamus Besar Kahasa Indonesia.

Yuniarsih, T., \& Suwatno. (2011). Manajemen 
6 Jurnal PILAR Nusa Mandiri Vol. 15, No. 1 Maret 2019

Sumber Daya Manusia; Teori, Aplikasi, dan Isu Penelitian (3rd ed.). Bandung: Alfabeta. 